\title{
Postantal Development of Renin-Angiotensin- Aldosterone System, RAAS, in Relation to Electrolyte Balance in Premature Infants
}

\author{
E. SULYOK, M. NÉMETH, I. TÉNYI, I. CSABA, E. GYÖRY, T. ERTL, AND F. VARGA
}

Department of Obstetrics and Gynecology, University of Pécs, Pécs, Hungary

\section{Summary}

In an attempt to provide information about the role of RAAS in development of late hyponatremia in low-birthweight neonates, simultaneous measurement of plasma renin activity, (PRA), plasma aldosterone concentration (PA), and urinary aldosterone excretion (UAE) was made using RIA methods along with determination of $\mathrm{Na}$ and $\mathrm{K}$ balance weekly up to the 6 th week of life. Seven healthy male infants with mean birthweight of $1580 \mathrm{~g}$, range: $1160-1850 \mathrm{~g}$, and mean gestational age of 31 weeks, range: $30-32$ weeks, were selected for the study.

Due to the increased urinary $\mathrm{Na}$ loss, negative $\mathrm{Na}$ balance developed in the first 2 weeks followed by positive balance thereafter. PRA, PA, and UAE increased tremendously from the initially high values of $18.2 \pm 4.1 \mathrm{ng} / \mathrm{ml} / \mathrm{hr}, 1.7 \pm 0.5 \mathrm{ng} / \mathrm{ml}$, and 2.6 $\pm 0.4 \mu \mathrm{g} / \mathrm{day}$, mean and SEM, to their maximum of $78.6 \pm 18.1$ $\mathrm{ng} / \mathrm{ml} / \mathrm{hr}, P<0.01,6.8 \pm 3.7 \mathrm{ng} / \mathrm{ml}, P<0.05$, and $26.4 \pm 2.9 \mu \mathrm{g} /$ day, $P<0.01$, in the 3rd week, respectively. Later on, gradual declines occurred, however, PRA, PA, and UAE remained highly elevated even at the 6th week with values of $45.5 \pm 15 \mathrm{ng} / \mathrm{ml} / \mathrm{hr}$, $1.6 \pm 0.5 \mathrm{ng} / \mathrm{ml}$, and $14.5 \pm 1.4 \mu \mathrm{g} / \mathrm{day}$, respectively.

It is suggested that late hyponatremia of premature infants is due to tubular unresponsiveness to aldosterone and not to inadequate response of RAAS to stimulation.

\section{Speculation}

The initially high urinary sodium excretion in premature infants is coupled with low urinary potassium excretion indicating limited renal sodium reabsorption in exchange for potassium. Later on, progressive increase in renal sodium-potassium exchange occurs and the plasma sodium and potassium concentrations gradually approach the normal values.

On the basis of these observations, one can assume the physiologic role of both the increasing activity of RAAS and also the increase in renal tubular responsiveness to aldosterone with advancing postnatal age.

It has been recently demonstrated that due to the increased urinary sodium loss in the first 2 weeks of life, negative sodium balance with subsequent hyponatremia develops in low birthweight premature infants fed with standard cow's milk formula (26).

This "physiologic" hyponatremia, which does not appear to have been previously recognized, starts in most after lst week, becomes progressively more severe for the 2 nd and 3 rd week, and then corrects itself by the 5th-6th weeks of life (26).

Although in the last 3 years several reports have been published confirming this first observation $(4,13,14,23)$, the pathogenic factors involved have not been clearly established. In view of the fact that the observed electrolyte pattern in plasma and urine is characteristic for hypoaldosteronism, it is tempting to postulate a causal relationship between physiologic hyponatremia and the function of renin-angiotensin-aldosterone system (RAAS) in low birthweight neonate.

In an attempt to obtain information about the role of RAAS in development of hyponatremia, the present study was undertaken to determine the postnatal changes of plasma renin activity (PRA), plasma aldosterone concentration (PA), and urinary aldosterone excretion (UAE) in relation to the electrolyte balance in premature infants during the first 6 weeks of life.

\section{MATERIALS AND METHODS}

The studies were performed on seven healthy male appropriate for dates premature infants. The mean birthweight and the gestational age of the infants was $1580 \mathrm{~g}$ and 31 weeks with the ranges of $1160-1850 \mathrm{~g}$ and $30-32$ weeks, respectively. The mothers were on normal diet without diuretic therapy, none had a history of renal disease or previous toxemia of pregnancy. All underwent uncomplicated vaginal delivery. Gestational age was assessed primarily from the mothers menstrual history, but was confirmed by physical examination of the infant. The 1-min Apgar score was more than 7 and the perinatal course remained uneventful in each case.

The infants were fed appropriate cow's milk formulas ("Robébi A") by a round the clock feeding pattern at 2-hourly intervals until they weighed about $1500 \mathrm{~g}$ and 3-hourly intervals, thereafter. The formula contained 71 calories, $2.1 \mathrm{~g}$ protein, $3.4 \mathrm{~g}$ fat, $8.0 \mathrm{~g}$ sugar, and $0.5 \mathrm{~g}$ minerals in $100 \mathrm{ml}$. Food intake was gradually increased in all infants to attain a calorie and fluid intake of 120 $140 \mathrm{cal} / \mathrm{kg}$ and $180-200 \mathrm{ml} / \mathrm{kg}$, respectively, by the end of the $2 \mathrm{nd}$ week of life. The maximum weight loss amounted to $6 \%$ on the 5 th postnatal day and the birthweight was regained by the 16 th day of life.

The intake and the urinary excretion of sodium and potassium as well as PRA, PA, and UAE were determined on the 7th day of life and in weekly intervals thereafter up to the 6th week of life. Urine was fractionally collected for a period of $24 \mathrm{hr}$. The specimens were refrigerated, pooled, and stored at $-20^{\circ} \mathrm{C}$ until analysis. PRA was measured radioimmunologically according to the method of Haber et al. (11) using SORIN-CEA-IRE RENK kits. $P A$ and urinary aldosterone concentration measurement was made by radioimmunoassay (28) using ALDOK RIA kits manufactured by SORIN-CEA-IRE (Italy). In our laboratory, the normal values in supine adults for PRA, PA, and UAE are $0.9 \pm 0.75 \mathrm{ng} / \mathrm{ml} / \mathrm{hr}$, $112 \pm 26 \mathrm{pg} / \mathrm{ml}$ and $10.9 \pm 1.1 \mu \mathrm{g} / 24 \mathrm{hr}$, respectively. The sensitivity of the method for PRA and PA is $0.2 \mathrm{ng} / \mathrm{ml} / \mathrm{hr}$ and 4 $\mathrm{pg} / \mathrm{ml}$, respectively. The interassay variation was $18 \%$ for PRA and $11 \%$ for PA. Formula and urinary sodium and potassium were measured by flame photometry. Statistical evaluation was done by using Student's $t$ test. 
RESULTS

\section{ELECTROLYTE BALANCES}

Sequential changes in intake, urinary excretion, and retention of sodium is shown in Figure la. It can be seen that sodium intake increased from $1.7 \mathrm{mEq} / \mathrm{kg} /$ day on the 7 th day to a value of 2.3 $\mathrm{mEq} / \mathrm{kg} /$ day by the 2 nd week and remained unchanged thereafter.

The urinary sodium excretion rate amounted to $3 \mathrm{mEq} / \mathrm{kg} / \mathrm{day}$ in the 1st week, much exceeding dietary intake. Subsequently, it steadily decreased and reached as low value as $0.9 \mathrm{mEq} / \mathrm{kg} /$ day at the end of the 5th week. As a result, negative sodium balance developed during the first 2 weeks of life followed by positive balance with sodium retention rate of $0.9-1.5 \mathrm{mEq} / \mathrm{kg} /$ day during the further periods of study.

Figure $1 \mathrm{~b}$ illustrates the postnatal changes in intake and urinary excretion of potassium as well as potassium retention rate. It is shown that the slightly increasing potassium intake is associated with a significant stepwise increase of renal potassium excretion reaching its maximum of $1.5 \mathrm{mEq} / \mathrm{kg} /$ day by the 4 th week.

Due to these changes, a continuously positive potassium balance developed and the amount of retained potassium increased at a slow rate until the 6 th week.

The apparent opposite trend of urinary sodium and potassium excretion during the first 4 weeks is reflected by the evolution of sodium/potassium ratio in the urine. Its highest value of 5.8 was found in the 1st week followed by a progressive decrease to attain a value of $2.9,1.5,1.0,0.9$, and 1.1 in the subsequent weeks, respectively (Fig. 1c).

\section{HORMONAL CHANGES}

The postnatal changes in PRA, PA, and UAE are represented in Figure 2. As it is shown, PRA, PA, and UAE much exceeded the normal values measured in adults already in the 1st week of life. The mean PRA of $18.2 \mathrm{ng} / \mathrm{ml} / \mathrm{hr}$ in the lst week significantly increased during the next 2 weeks and reached its maximum of $78.6 \mathrm{ng} / \mathrm{ml} / \mathrm{hr}$ by the end of the 3rd week $(P<0.01)$. Later on, PRA gradually declined from this very high value, however, it remained as high as $45.5 \mathrm{ng} / \mathrm{ml} / \mathrm{hr}$ at the end of the study (Fig. 2a).

PA showed a very similar pattern to that of PRA (Fig 2b). The initial value of $1.7 \mathrm{ng} / \mathrm{ml}$ observed in the $1 \mathrm{st}$ week is followed by a continuous rise reaching its peak value of $6.8 \mathrm{ng} / \mathrm{ml}(P<0.05)$ in the 3rd week of extrauterine life. Thereafter, PA gradually falls to a value of $1.6 \mathrm{ng} / \mathrm{ml}$ at the end of the observational period ( $P$ $<0.05$ ).

The sequential changes in UAE are shown in Figure $2 \mathrm{c}$. The changes with time were rather similar to those of PA, but the maximal rate of UAE occurred later in the 4th week and it was about 10 times higher than the initial value as compared with a 4fold increase taking place in the 3 rd week in PA.

The similar trend and time course of changes in PRA, PA, and UAE point towards a close relationship between these parameters and suggest that all respond in a rather similar manner to the

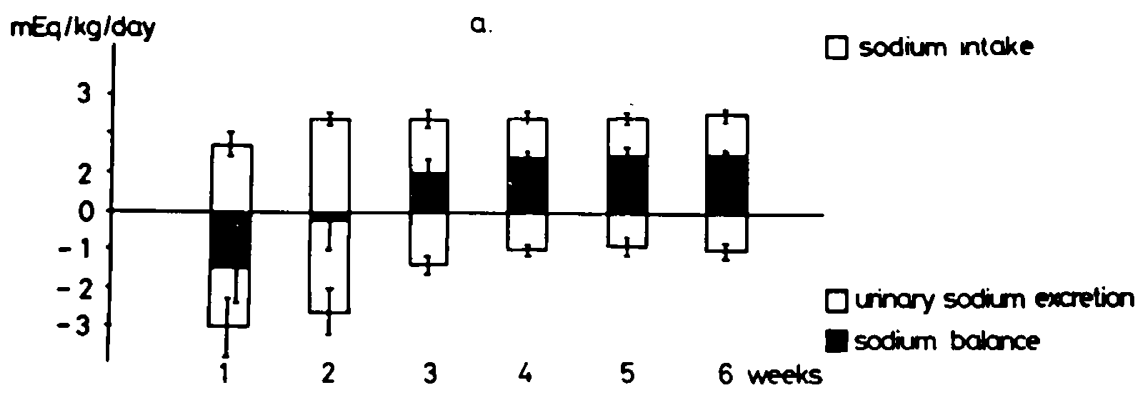

b.
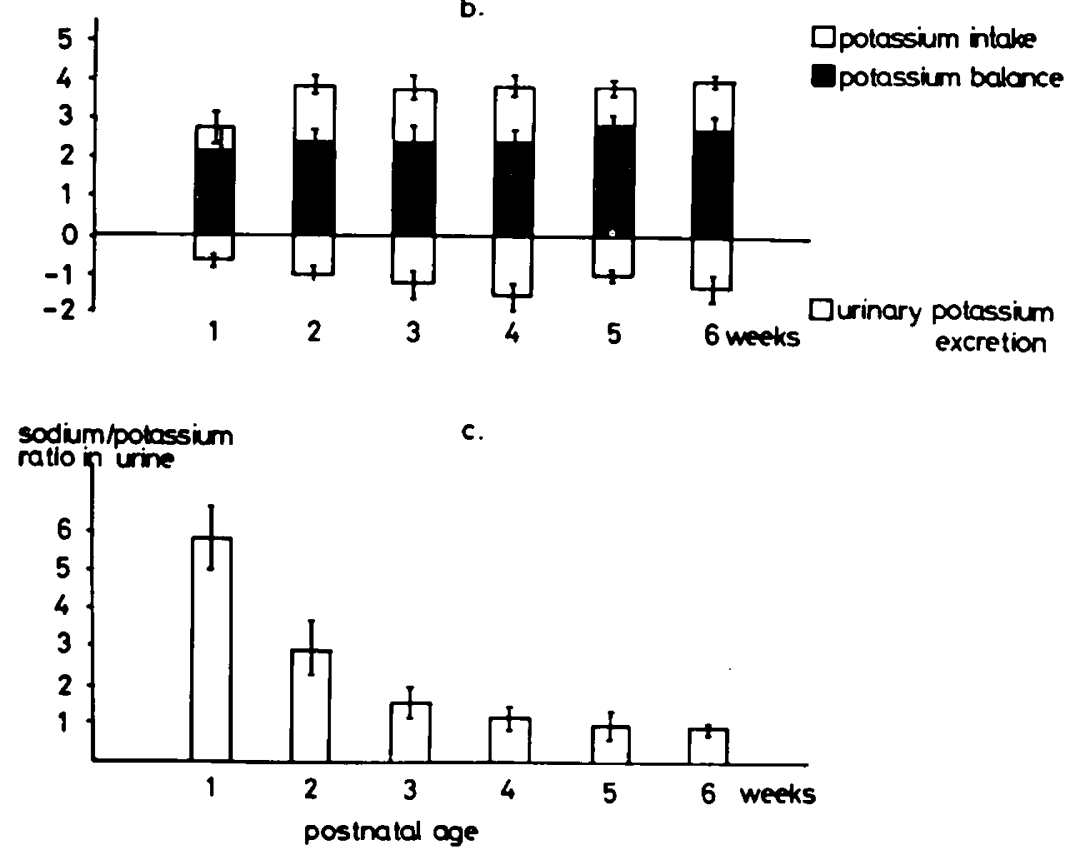

Fig. 1. Postnatal changes in sodium (a) and potassium balances (b), as well as in urinary sodium/potassium ratio (c) of premature infants during the first 6 weeks of life. The vertical bars represent the SEM. 


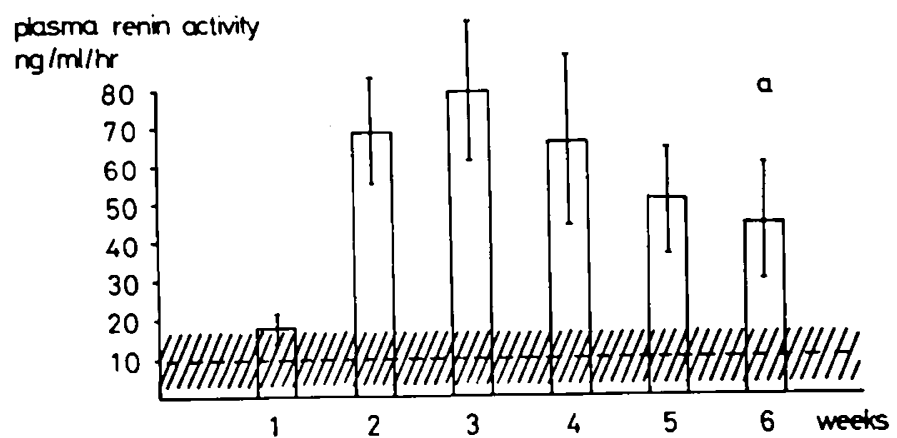

plasma abdosterone concentration $\mathrm{ng} / \mathrm{ml}$
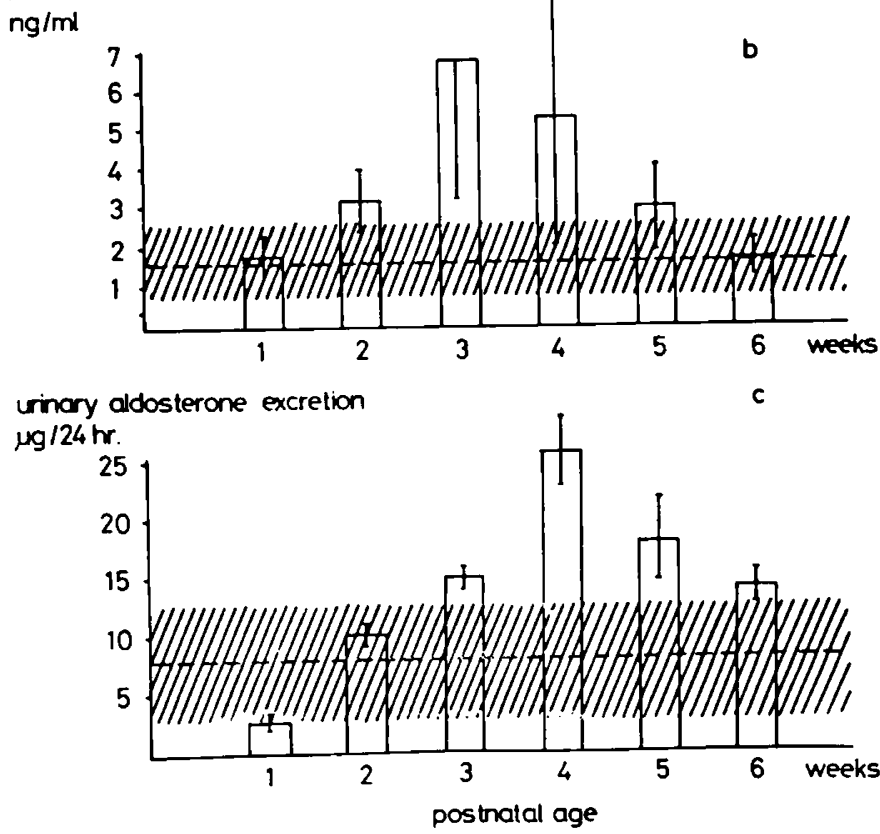

Fig. 2. Postnatal changes in PRA (a), PA (b), and UAE (c) of premature infants during the first 6 weeks of life. The vertical bars represent the SEM The hatched area indicates the normal value (mean $\pm \mathrm{SD}$ ) for 1-week-old full-term neonates.

changes occurring in electrolyte balance during the early postnatal life.

\section{DISCUSSION}

In the present study, an attempt was made to complete our earlier works describing the characteristic developmental pattern of urinary excretion and plasma concentration of sodium and potassium in low birthweight premature infants $(16,26)$. The recent introduction of the sensitive radioimmunoassay methods for measurements of PRA and PA using small quantity of blood made it possible to determine weekly the sequential changes in PRA and PA during a period of 6 weeks and to relate them to the changes occurring in electrolyte balances and in particular in plasma sodium and potassium concentrations described in previous studies $(4,13,14,23,26)$.

The present findings confirmed the earlier results that, in premature infants, due to the relatively high renal sodium loss after birth, negative sodium balance develops and the positive sodium balance can only be restored after the 2 nd week of life.

It has been suggested that several factors may be involved in producing increased urinary sodium loss in infants with low birthweight and young age $(1,19)$. The main factors to be taken into account are: extracellular volume expansion (3), high relative sodium content of the body (18), functional and morphologic glomerulo-tubular imbalance (8), functional nephron heterogenity $(6,7)$, tubular unresponsiveness to mineralocorticoids $(10)$, the limited renal hydrogen ion production for tubular $\mathrm{Na}^{+}-\mathrm{H}^{+}$exchange $(16,27)$, and the alterations in the kinetics of enzyme reactions underlying transport mechanism (19).

The relative importance of each of these factors is uncertain, further studies are required to enlighten their contribution to the decreased tubular reabsorption of sodium. The role of RAAS in sodium homeostasis of premature infants is a matter of considerable interest, but not well understood. In a series of recent publications, it was reported that PRA $(5,9,12,15,17,25)$, plasma angiotensin $(9,17,20)$, and PA $(2,5,9,15,21,24,25)$ are higher in the immediate neonatal period than in older infants, children, and adults. However, longitudinal studies have not been performed to clarify its participation in controlling sodium homeostasis particularly with respect to the late hyponatremia.

In search of the relationship between aldosterone status and sodium homeostasis in preterm infants, Honour et al. (14) reported that the negative sodium balance and hyponatremia during the first 2 weeks of life was associated with an excretion of tetrahydroaldosterone comparable with full-term infants, but it was significantly elevated during the 3 rd week when positive salt balance could be established. The results were regarded to indicate an increased aldosterone secretion in response to negative sodium balance. Unfortunately, PRA and PA was not measured (14).

In a preliminary study on postnatal development of PRA in four preterm infants by Richer et al. (22), PRA was found to be very high in the 2-3 weeks and it decreased thereafter. Neither PRA in the first 2 weeks, nor electrolyte balance and aldosterone status were determined in the study (22).

In good agreement with these results, our finding can be interpreted as providing suggestive evidence that as a consequence of negative sodium balance and hyponatremia the initially high PRA, PA, and UAE are further augmented, but they tend to decline with restoring positive sodium balance and rising plasma sodium concentration.

On the basis of these findings, it is relevant to assume that the increased urinary sodium loss and the development of late hypoantremia in low birthweight premature infants might rather be due to renal tubular unresponsiveness to aldosterone than to inadequate response of RAAS to stimulation. However, as an alternative explanation, it should also be considered that the proximal tubular reabsorption of sodium is deficient which results in increased delivery of sodium into the distal nephron. Consequently, even the increased rate of aldosterone secretion proves to be insufficient to overcome this excessive proximal natriuresis and to maintain sodium balance.

\section{CONCLUSION}

Postnatal development of PRA, PA, and UAE was measured in relation to electrolyte balance in seven healthy premature infants during the first 6 weeks of life. It was found that due to the increased urinary sodium loss, negative salt balance developed in the first 2 weeks and it could only be restored thereafter.

In response to the negative salt balance, the initially high values of PRA, PA, and UAE were further augmented and reached their maximum at the 3 rd -4 th weeks followed by a gradual decrease until the end of the study.

It was concluded that, in premature infants, RAAS responds adequately to stimulation, therefore, it can not be regarded as a cause of renal salt wasting and late hyponatremia.

\section{REFERENCES AND NOTES}

1. Aperia, A., Broberger, O., Thodenius, K., and Zetterström, R.: Developmental study of the renal response to an oral salt load in preterm infants. Acta Paediatr. Scand. 63: 517 (1974).

2. Beitins, I. Z., Bayard, F., Levitsky, L., Ances, I. G., Kowarski, A., and Migeon, C. J.: Plasma aldosterone concentration at delivery and during the newborn period. J. Clin. Invest., 51: 386 (1972).

3. Cassady, G.: Bromide space studies in infants of low birth weight. Pediatr. Res. 4: 14 (1970).

4. Day, G. M., Radde, I. C., Bafle, J. W., and Chance, G. W.: Electrolyte abnormalities in very low birthweight infants. Pediatr. Res., 10: 522 (1976).

5. Dillon, M. J., Gillon, M. E. A., Ryness, J. M., and deSwiet, M.: Plasma renin 
activity and aldosterone concentration in the human newborn. Arch. Dis. Childhood 51: 537 (1976).

6. Edelmann, C. M., Boichis, H., Soriano, J. R., and Stark, H.: The renal response of children to acute ammonium chloride acidosis. Pediatr. Res., 1: 452 (1967)

7. Edelmann, C. M., Soriano, J. R., Boichis, H., Gruskin, A. B., and Acosta, M. L.: Renal bicarbonate reabsorption and hydrogen ion excretion in normal infants. J. Clin. Invest., 46: 1309 (1967)

8. Fettermann, G. H., Shuplock, N. A., Philop, F. J., and Gregg, H. S.: The growth and maturation of human glomeruli and proximal convolutions from term to adulthood: studies by microdissection. Pediatrics, 35: 601 (1965).

9. Godard, C., Gaillard, R., and Vallotton, M. B.: The renin-angiotensin-aldosterone system in mother and fetus at term. Nephron, 17: 353 (1976).

10. Greenberg, A.: Renal tubular response to aldosterone in normal infants and children with adrenal disorders. J. Clin. Endocrinol. Metab., 27: 1197 (1967).

11. Haber, E., Koerner, T., Page, L. B., Kliman, B., and Purnode, A.: Application of a radioimmunoassay for angiotensin I to the physiologic measurements of plasma renin activity in normal human subjects. J. Clin. Endocrinol. Metab., 29: 1349 (1969).

12. Hayduk, K., Krause, D. K., Huengers, R., and Unbehaun, V.: Plasma renin concentration at delivery and during the newborn period in humans. Experimentia, 28: 1489 (1972).

13. Honour, J. W., Valman, H. B., and Shackleton, C. H. L.: Sodium homeostasis in preterm infants. Lancet, 2: 1147 (1974).

14. Honour, J. W., Valman, H. B., and Shackleton, C. H. L.: Aldosterone and sodium homeostasis in preterm infants. Acta Pediatr. Scand., 66: 103 (1977).

15. Katz, F. H., Beck, P., and Makowski, E. L.: The renin-aldosterone system in mother and fetus at term. Am. J. Obstet. Gynecol., 118: 51 (1974).

16. Kerpel-Fronius, E., Heim, T., and Sulyok, E.: The development of the renal acidifying processes and their relation to acidosis in low birth-weight infants. Biol. Neonate. 15: 156 (1970).

Copyright (C) 1979 International Pediatric Research Foundation, Inc $0031-3998 / 79 / 1307-0817 \$ 02.00 / 0$
17. Kotchen, T. A., Strickland, A. L., Rice, T. W., and Walters, D. R.: A study of the renin-angiotensin system in newborn infants. J. Pediatr., 80: 938 (1972).

18. McCance, R. A., and Widdowson, E. M.: Mineral metabolism of the foetus and newborn. Brit. Med. Bull., 17: 132 (1961).

19. Metcoff, J.: Synchrony of organ development contributing to water and electrolyte regulation in early life. Clin. Nephrol., $1: 107$ (1973).

20. Pipkin, F. B., and Smales, O. R. C.: Blood pressure and angiotensin II in the newborn. Arch. Dis. Childhood, 50: 330 (1975).

21. Raux-Eurin, M. C., Pham-Huu-Trung, M. T., Marrec, D., and Girard, F.: Plasma aldosterone concentrations during the neonatal period. Pediatr. Res., 11:182 (1977).

22. Richer, C., Hornych, H., Amiel-Tison, C., Relier, J-P., and Ciudicelli, J-F. Plasma renin activity and its postnatal development in preterm infants. Preliminary report. Biol. Neonate, 31: 301 (1977)

23. Roy, R. N., Chance, G. W., Radde, I. C., Hill, D. E., Wills, D. M., and Sheepers, J.: Late hyponatremia in very low birthweight infants (1.3 kilograms). Pediatr. Res., 10: 526 (1976).

24. Siegel, S. R., Fisher, D. A., and Oh, W.: Serum aldosterone concentrations related to sodium balance in the newborn infants. Pediatrics, 53:410 (1974).

25. Siegler, R. L., Crouch, R. H., Hackett, T. N., Walker, M., and Jubiz, W. Potassium-renin-aldosterone relationship during the first year of life. J. Pediatr., 91: 52 (1977).

26. Sulyok, E.: The relationship between electrolyte and acid-base balance in the premature infant during early postnatal life. Biol. Neonate, 17: 227 (1971).

27. Sulyok, E., Heim, T., Soltész, G., and Jászai, V.: The influence of maturity on renal control of acidosis in newborn infants. Biol. Neonate, 21: 418 (1972).

28. Vetter, W.: Radioimmunoassay for aldosterone without chromatography. Determination of plasma aldosterone. Acta Endocrinol., 74: 558 (1973).

29. Received for publication April 7, 1978.

30. Accepted for publication July 27, 1978. 